\title{
Comparative Study of the Renewal Information of Granted Patents in the Physics Technological Field in China, France and Germany
}

\author{
Yongzhong Qiao, a , Wanlin Tan ${ }^{1, b}$ \\ ${ }^{1}$ Intellectual Property Research Institute, Xiamen University, Xiamen, 361005, P.R.China \\ aqyzh1@qq.com, ${ }^{b} 892926507 @ q q . c o m$
}

\begin{abstract}
Keywords: physics technological field; granted patents; renewal information.
Abstract. Comparative study of the claim number, the examination time, the inventor number and the maintenance time of granted patents in the physics technological field in China, France and Germany in 1994, conclusions as following: the patents renewal time is mainly decided by the qualities or values of patents, and these information is influenced by the patent systems of countries and the patent management capabilities of patentee, and the difference of patents renewal information has a specific expression in the physics technological field. What's more, the average number of claims, the average examination time, the average inventor number and the average maintenance time of patents granted by China is lower than that of patents granted by France and Germany in this technological field.
\end{abstract}

\section{Introduction}

The information of patent renewal is a critical index to measure the quality of patents in a country, which protect inventions and reinforce information reported to investors about the quality of inventions. $^{[1]}$ The International Patent Classification System (IPC) was established by the Strasbourg Agreement in 1971, which divides technological fields into eight sections. IPC is a hierarchical language of independent symbols in the classification of patents. The quality of a patent is strongly and significantly correlated with the technological field. The Physics technological field belongs to the seventh section in IPC. The innovation research in this technological field is very important for the development of economy and the advancement of physics technology. Therefore, the purpose of this study is to found the difference of renewal information of patents in physics technological field granted by different countries.

Due to the locality of the patent system, there are different patent granted systems and the patent renewal systems in different countries. Yi Deng (2005) examined the joint patent designation renewal behavior of the EPO patent applicants during 1978 to 1996, discovering that the European patents granted by the EPO are substantially more valuable than patents through the national route. The value of patent rights increases with the economics size of the country and has a modestly increasing return to scale. The model estimation also reveals significant institutional differences across different EPO member countries in patent protections and quantifies them. ${ }^{[2]}$ As technical characteristics in different technological fields may vary, for the patent renewal in specific technology area, Gronqvist ( 2009 ) discovered that there are large differences in values between technologies, and the higher level of patent protection can bring larger gains. ${ }^{[3]}$ Yongzhong Qiao (2011) believes that the patents maintenance time of the electricity technological field and the physics technological field is more than that of other technological fields. ${ }^{[4]}$ Shuang Song and Xiangdong Chen (2013) investigated the entire patents of information technological field granted by China from 1985 to 2009, and the results showed that the median survival period in information technological field is approximately 10.5 year, only $1 \%$ patents maintain until expiration; the maintenance status of American applicants remains the best, while the overall maintenance period of Chinese applicants is the shortest. ${ }^{[5]}$ Xiaohui Cao, Yibing Duan through analyzed 1,063 genetic engineering patents granted by US during 1991-1996, and founded that genetic engineering patents have a high renewal rate, and $61 \%$ patents owned by large entities are renewed to full time and the average age is 13.65 years. ${ }^{[6]}$ Overview of the previous research found that there are a few of research results for the comparative study of the patent renewal information in the specific 
technology granted by different countries, so the purpose of this research is to analyze the maintenance status of patents in the physics technological field granted by different countries.

As the advanced industrial counties, France and Germany have strong technological innovation ability. According to the data, the research group has found that the maintenance time of patents granted by Germany is higher than that of other two counties. Comparative analysis of the maintenance status of patents granted by China, Germany and France is not only conducive to understanding the regularity of patent renewal in a specific technological field, but also find the capacity gaps of the patent management and utilization of patentees among different countries.

\section{Data collection and the establishment of database}

In this paper, all data from the database provided by State Intellectual Property Office of the People's Republic of China (SIPO), German Patent and Trade Mark Office (DPMA), French Industrial Property Office (INPI), 3,838 samples were randomly extracted from patents granted by China, Germany and France in $1994^{1}$, and the database of patents granted by China in 1994, the database of patents granted by Germany in 1994, the database of patents granted by France in 1994 were formed. Extracting physics selection patents data in the above data set, the database of the physics patents granted by China, Germany, and France in 1994 were formed. Based on this database, the claim number, the inventor number, the examination time and the maintenance time of granted patents in China, France and Germany will be researched.

\section{Information analysis of granted patents in physics technological field in China, France and Germany}

\section{Analysis of the claim number of granted patents in physics technological field in China, France and Germany}

Claims are a part of a patent application that defines the scope of protection granted by the patent. ${ }^{[7]}$ The claim numbers include the number of independent claims and the number of dependent claims, and they reflect not only the complexity of the technology protected by patents, also reflect the characteristics of the patentee claims composition and decision-making on the scope of protection. Figure 1 shows the distribution of the claim numbers of granted patents in the physics technological field in China, France and Germany.

Figure 1 indicates that the range of claim numbers of the granted patents in the physics technological field in China, France and Germany are large, and the minimum value of claim numbers are 1 , the maximum value of claim numbers are $79,62,84$ respectively. When the claim number of the granted patents in the physics technological field in China is 3, the percentage of patents in the physics technological field is largest, and account for $9 \%$ of all granted patents in this technological field. When the claim number of granted patents is 10 , the percentage of granted patents in the physics technological field in France is largest, account for $11.5 \%$ of all granted patents in this technological field. When the claim number of granted patents is 6 , the percentage of granted patents in the physics technological field in Germany is largest, account for $9.5 \%$ of all granted patents in this technological field. These partly reflect the feature that patentee tend to protect patent right with less claim number of granted patents in the physics technological field in China. More uniformity trend is that the claim number of granted patents in this three counties concentrated on one to eighteen, when the claim number are greater than eighteen, the percentage of granted patents in the physics technological field are less than $2 \%$. The claim context and the claim number of a patent are decided by the characteristics of technological innovations. The reasonable context and the claim number of a patent should be able to meet the principle of full disclosure of the patent, maximize their scope of patent protection, and avoid the patent right are imitated by other people. Therefore, the claim number of patent is not better of more or less, but need on the basis of technical solutions to choose. What's interesting in this paper found is that when the claim 
number are more than 18, the percentage of patents which granted in the physics technological field by China, France or Germany is extremely low. Therefore, even in different countries, as the complexity of technology has some characters in a specific technological field, the writing method of patent claims will also have a certain degree convergence. We may safely draw the conclusions from the above analysis that technical features of the Physics technological field make the large range of the claim number of patents for protection of patent rights, and the patentee tend to use less than 18 claims for their patent protection.

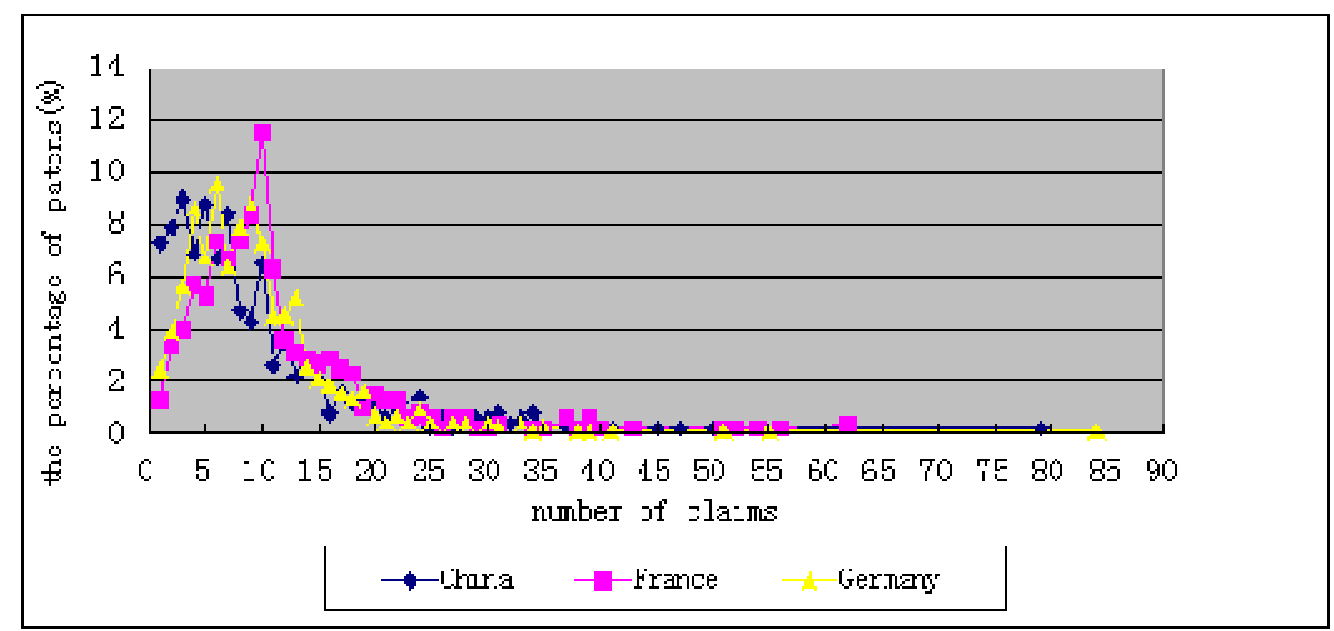

Fig 1. Distribution of the claim number of granted patents in physics technological field in China, France and Germany

\section{Analysis of the examination time of granted patents in physics technological field in China, France and Germany}

The examination time of patents refers to the time gap between the filing and granting date of patents. This period is the time to wait and review the application for patent in the patent office. Whether in China, France or Germany, a statutory protection period is twenty years from the date of filing and specific areas can be appropriately extended. The length of examination time of granted patents will not only affect the patent duration, but also affect the applicant's costs and the length of endurance, the greater the expected profit of applicants for patents is, the stronger the patentee's endurance for the patent examination time is, otherwise they will give up patent applications. ${ }^{[8]}$

Figure 2 shows that the range of the examination times of granted patents in the physics technological field in China, France and Germany are one to nine years, one to six years and one to seventeen years respectively. In other words, all the minimum value of the examination time of granted patents in the physics technological field in this three countries are one year, but the maximum value of the examination time in the physics technological field patents granted by China, France and Germany are nine years, six years and seventeen years respectively. And patents granted by Germany have the widest range of examination time. From figure 2, we note that the distribution of examination time of patents in the physics technological field granted by this three countries have two aspects in common: first, the examination time centralized distributed on three to five years, the largest percentage of the examination time of patents granted by China, France and Germany are three years (account for 29.5\%), four years (account for 34\%) and five years (account for $25.6 \%$ ) respectively; second, with the examination time increases, the percentage of granted patents first increase and then decrease. 


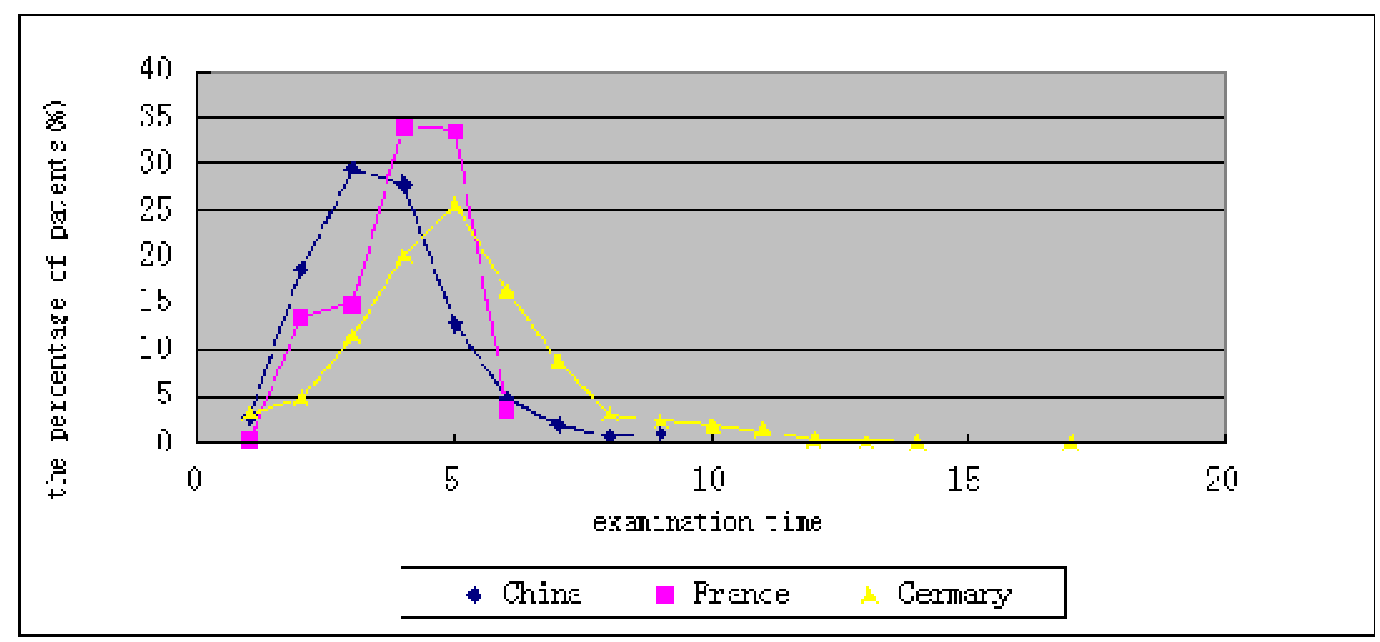

Fig 2. Comparative analysis of the examination time of granted patents in the physics technological field in China, France and Germany

\section{Analysis of the average inventor number of granted patents in the physics technological field in China, France and Germany}

The inventor number of each granted patent may reflect the complexity of patent and the investment of human resource for patent. Figure 3 shows the comparison of the average inventor number of granted patents in the physics technological field in China, France and Germany.

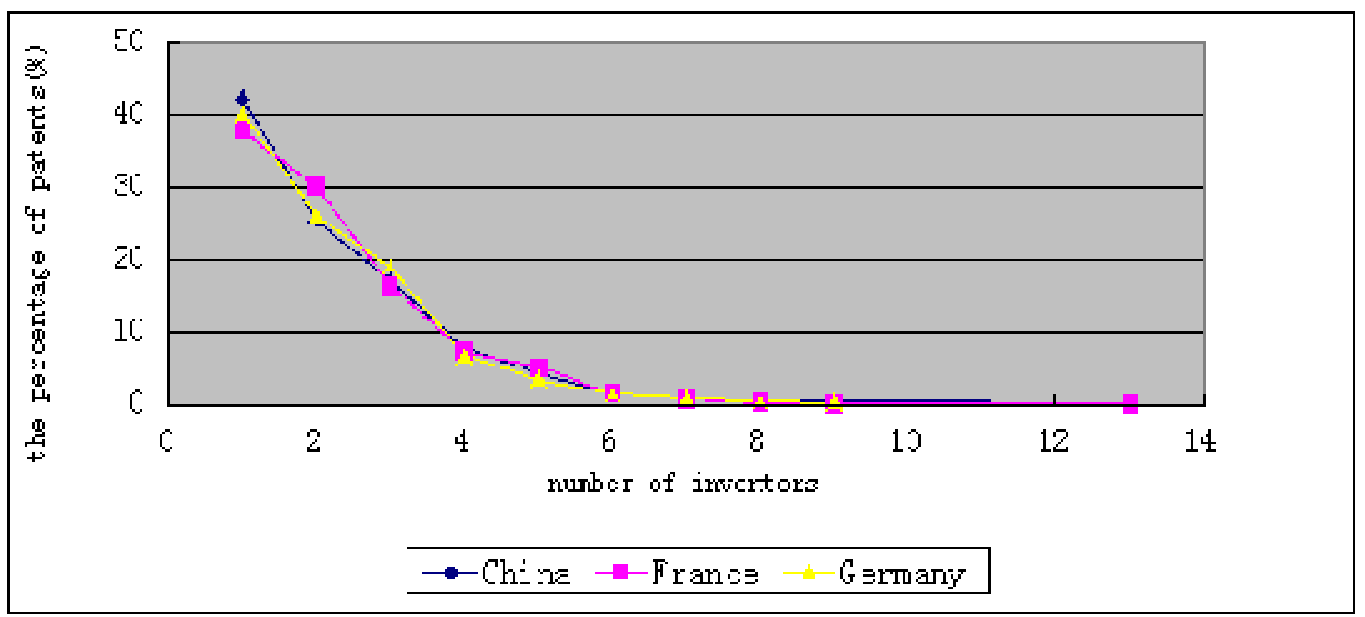

Fig 3. Comparative analysis of the average inventor number of granted patents in physics technological field in China, France and Germany

Figure 3 shows that the distributions of average inventor number of granted patents in the physics technological field in three countries are basically same. With the average inventor number increased, the percentage of patents number all gradually reduced. When the average inventor number is one, the largest percentage of granted patents in the physics technological field in China, France and Germany are $42.2 \%, 37.8 \%$ and $40.1 \%$ respectively. So in the physics technological field, the cooperation rate of patent inventors is not high. The cooperation rate of patent inventors refers to the quantity proportion of the patents number that there are two or more than two inventors to all patents number. ${ }^{[9]}$ When the average inventor numbers of patents are greater than or equal to six, the percentages of granted patents in these three countries are lower than $2 \%$ of all granted patents in this technological field. The maximum values of average inventor numbers of granted patents in the physics technological field in China, France and Germany are thirteen, thirteen and ten respectively. The distributions of average inventor number of patents granted by these three countries are all concentrated on one to three. The highly consistent degree of distribution in the inventor number proved that the technical characteristics of a particular technological field have some rule for the characteristics of patent renewal information. 


\section{Comparative analysis of the interval scale of granted patents in the physics technological field in China, France and Germany}

By comparing the mean values of each variable for patents in the physics technological field granted by China, France and Germany, we notice that the mean number of inventors of patents granted by this three countries are very close, but there are different of the mean number of claim, the examination mean time and the maintenance mean time (table 1).

\begin{tabular}{|c|c|c|c|c|c|}
\hline & & $\begin{array}{l}\text { claim } \\
\text { number }\end{array}$ & $\begin{array}{l}\text { inventor } \\
\text { number }\end{array}$ & $\begin{array}{l}\text { examination } \\
\text { time }\end{array}$ & $\begin{array}{l}\text { maintenance } \\
\text { time }\end{array}$ \\
\hline \multirow{2}{*}{ China } & Mean value & 9.49 & 2.21 & 3.61 & 8.12 \\
\hline & standard deviation & 8.864 & 1.515 & 1.416 & 5.414 \\
\hline \multirow[t]{2}{*}{ France } & mean value & 11.3 & 2.25 & 3.98 & 10.37 \\
\hline & standard deviation & 8.523 & 1.473 & 1.099 & 3.979 \\
\hline \multirow[t]{2}{*}{ Germany } & mean value & 9.72 & 2.23 & 5.09 & 8.79 \\
\hline & standard deviation & 7.371 & 1.483 & 2.115 & 4.606 \\
\hline
\end{tabular}

The table 1 shows the differences of mean values of claim number, the inventor number, the examination time and the maintenance time of granted patents in the physics technological field in China, France and Germany. Firstly, the maximum of average claim number of granted patents in the physics technological field in France is 11.3 items, but the mean value of claim number of granted patents in China and Germany are close, and the mean values are 9.49 items and 9.72 items respectively; Secondly, for the mean value of inventor number, there are a few different in the granted patents in the physics technological field in China, France and Germany, and the mean number of inventors are about two persons; Thirdly, the average examination time (5.09 years) of granted patents in Germany are more than that of granted patents by China and by France in the physics technological field, whose mean examination time are three years or so; Finally, the maximum of mean value of maintenance times of granted patents in the physics technological field in France is about 10.37 years, and the minimum value of the granted patents in the physics technological field in China is 8.12 years. In addition, there are different in the standard deviation of the average claim number, the average number of inventors, the average examination time and the average maintenance time of granted patents in the physics technological field in China, France and Germany.

\section{Comparative analysis of the abandoned patents number in the physics technological field granted by China, France and Germany}

The patent maintenance time refers to the length of time that patent from granted to abandon. It reflects the patent usage and management status, also reflects the duration of patents bring returns for patentees. ${ }^{[10]}$ So, we can use the variable "patent maintenance time" to research the difference of the value or quality of patents in the physics technological field granted by China, France and Germany. According to the patent maintenance annual fee system of China, we divide the maintenance time into one to three years, four to six years, seven to nine years, ten to twelve years, thirteen to fifteen years and sixteen to twenty years after patents were granted, and to analyze the abandoned patents number in the physics technological field granted by China, France and Germany in six maintenance periods.

Figure 4 shows that the trends of the distribution of abandoned patents in the physics technological field granted by China, France and Germany are different. With the maintenance time increased, the percentage of abandoned patents in the physics technological field granted by China presents the trend of increased after decreased first. When the maintenance time of patents granted by China is one to three years, four to six years, seven to nine years, ten to twelve years, thirteen to 
fifteen years and sixteen to twenty years, the percentage of abandoned patents is $27.7 \%, 20 \%$, $15.9 \%, 7.2 \%, 13.7 \%$ and $14.5 \%$ respectively. In the maintenance time of one to three years, the percentage of abandoned physics patents granted by China is the most to $27.7 \%$, and in stark contrast to the patents of granted by France, the percentage of abandoned patents in this period is 0 , and the percentage of abandoned patents in the physics technological field granted by France presents the fluctuating trends with the maintenance time increased, when the patent maintenance time is thirteen to fifteen years, the percentage of abandoned patents is the maximum of all, account for $25.3 \%$. For the granted patents in the physics technological field in Germany, when the maintenance time of patents is one to three years, four to six years and seven to nine years, the percentage of abandoned patents gradually has increased, and when the maintenance time of patents is seven to nine years, the percentage of abandoned physics patents is the highest (24\%), but when the maintenance time of patents is ten to twelve years, thirteen to fifteen years and sixteen to twenty years, the percentage of abandoned patents in the physics technological field first increased and then decreased with the increasing of maintenance time. The distribution of abandoned patents in physics technological field granted by China, France and Germany indicates that when the maintenance time of patents are one to three years and sixteen to twenty years, the percentage of abandoned patents in the physics technological field granted by China is higher than that of patents granted by France and Germany, this partly reflects the maintenance time of patents in the physics technological field granted by China has the characteristic of two extremes distribution, while the distribution of maintenance time of patents granted by Germany and France are focused on four to six years, seven to nine years, ten to twelve years, thirteen to fifteen years, and their distribution are more balanced.

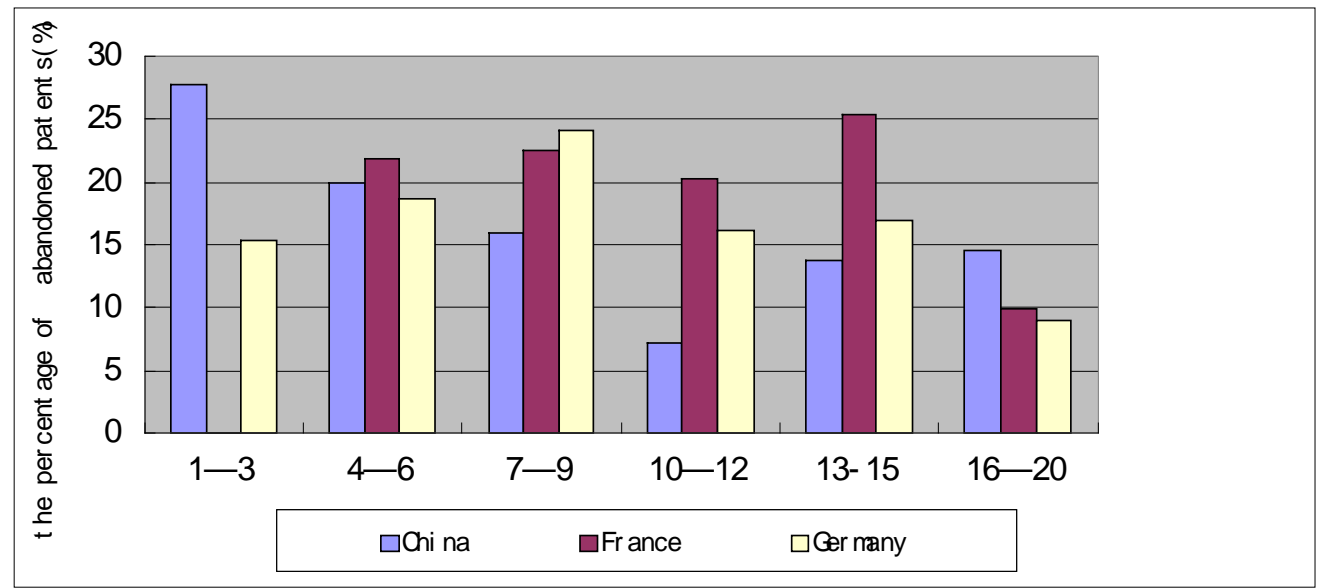

Fig. 4. Distribution of abandoned patents in the physics technological field granted by China, France and Germany

\section{Conclusions}

Although there are different patent systems in different countries, the convergence of technical characteristics make the closing gap of patent information of patents granted by different countries in a particular technology field. From the analysis results of the claim number, the examination time, the inventor number and the maintenance time of granted patents in China, France and Germany, conclusions can be drawn as following: first, different patent systems and patent management capabilities lead to different patent renewal information, but in the specific technological field, the difference will be shrink; second, the average number of claim, the average examination time, the average number of inventors and the average maintenance time of patents granted by China are lower than that of patents granted by France and Germany. Therefore, even if there are different patent systems in different countries and patentee has different abilities of patent management that can cause differences in patent maintenance the consistency of the technical characteristics of a particular technological field will narrowed these differences. On the other hand, 
we should aware that as the policy stimulus and companies deepened the understanding of the importance of patents, filings of patent application in China fast-growing steadily in recent years, but compared to Germany, France and other industrial countries, the patent management ability and the ability to use patents of patentees in China are relatively inferior.

\section{Acknowledgements}

This work was financially supported by the National Natural Science Foundation of China (batchnumber: 71373221)

\section{References}

[1] L. Hikkerova, N. Kammoun, J.S. Lantz, Patent Life Cycle: New Evidence. Technological Forecasting and Social Change. 88 (2014) 313-324.

[2] Y. Deng, Private Value of European Patents. European Economic Review. 51 (2007) 1785-1812.

${ }^{[3]} \mathrm{C}$. Gronqvist, The Private Value of Patents by Patent Characteristics: Evidence from Finland. The Journal of Technology Transfer. 34 (2009) 159-168.

[4] Yongzhong Qiao, Empirical Study on the Patent Maintenance Information in the Different Technological Fields. Library and Information Service. 6 (2011) 36-39. (in Chinese)

[5] Shuang Song, Xiangdong Chen, Research on Patent Maintenance and Its Influencing Factors in the Field of Information Technology. Library and Information Service.18 (2013) 98-103,132. (in Chinese)

[6] Xiaohui Cao, Yibing Duan, Genetic Engineering Patent Renewal Characters and Their Influencing Factors. Science Research Management. 2 (2012) 26-32. (in Chinese)

[7] D. Rohde, Lucent Hardball, 16. 12 Network World (1999).

[8] Yongzhong Qiao, The Factors Affecting the Patent Maintenance Time. Science Research Management. 7 (2011) 143-149,164.

[9] Chunjuan Luan. Patent metrics and Studies on Developing Model of Patent. Dalian University of Technology. (2008) 102-105.

[10] Yongzhong Qiao, A Theoretical and Empirical Research on the Patent Maintenance System. Hua zhong University of Science and Technology. (2010) 35-51. (in Chinese) 